\title{
Martılarda (Laridae spp.) Cranium'un Üç Boyutlu Modellemesi
}

\author{
Nazan GEZER iNCE ${ }^{1}$, İsmail DEMiRCioĞLU²*, Bestami YILMAZ², Adem AĞYAR ${ }^{3}$, Abdurrahim DUSAK $^{3}$ \\ ${ }^{1}$ İstanbul Üniversitesi, Veteriner Fakültesi, Anatomi Anabilim Dalı, Avcılar, İstanbul, Türkiye. \\ ${ }^{2}$ Harran Üniversitesi, Veteriner Fakültesi, Anatomi Anabilim Dalı, Şanlıurfa, Türkiye. \\ ${ }^{3}$ Harran Üniversitesi Tıp Fakültesi, Radyoloji Anabilim Dalı, Şanlıurfa, Türkiye.
}

Geliş Tarihi: 06.03.2018

Kabul Tarihi: 07.05.2018

\begin{abstract}
Özet: Bu çalışma, martı cranium'larına ait osteometrik özellikleri ve diğer kanatlı hayvan türleri ile aralarındaki farklılıkları ortaya koymak amacıyla yapıldı. Çalışmada, cinsiyet ve tür farkı gözetilmeden toplanan 15 adet ölü martı kullanıldı. Diseksiyon yöntemiyle gövdeden ayrılan martı cranium'ları 64 dedektörlü bilgisayarlı tomografi (General Electronic Revolution) cihazı ile tarandı. Elde edilen aksiyal kesitsel görüntülerden 3D formatında görüntüler oluşturuldu. Oluşturulan bu üç boyutlu görüntüler üzerinde belirlenen ölçüm noktalarından osteometrik ölçümler alındı. Elde edilen ölçüm verileri ile istatistiksel değerlendirmeler yapıldı. Laridae familyasına ait olan martıların cranium'larının Multi Dedektör Bilgisayarlı Tomografi görüntüleri üzerinden alınan ölçümlerinde istatistiki olarak $\mathrm{P}<0.01$ ve $\mathrm{P}<0.05$ düzeyinde önem ilişkisi taşıyan veriler tespit edildi. Bu verilerin belirlenmesiyle martı cranium anatomisinin daha iyi anlaşılacağı, taksonomik yerinin belirlenmesinde referans veriler sunacağı ve bu konuda sınırlı olan literatürlere de katkı sağlanacağı düşünüldü.

Anahtar Kelimeler: Cranium, Martı, Bilgisayarlı tomografi, Morfometri.
\end{abstract}

\section{Three-Dimensional Modeling of Cranium in Seagulls (Laridae spp.)}

Abstract: This study was performed to investigate osteometrical measurements of cranium in seagulls and to compare it with other birds. In this study, 15 cranium samples from dead seagulls were used without considering sex and species differences. Craniums seperated from the body by the method of dissection were scanned with a 64-slice computer tomography (CT) device. Results from CT were modelled in three-dimension (3D) format and osteometrical measurements were performed on the 3D models. Results were evaluated statistically and Multi Detector Computed Tomography results for the Laridae family showed significantly related results $(P<0.01$ and $P<0.05)$. The results of the study provided reference measurements for better understanding the cranium anatomy and facilitating taxonomical classification of seagulls. The study might also be a useful additional resource in regards to currently limited literature on seagull cranium anatomy.

Keywords: Cranium, Seagull, Computed tomography, Morphometry.

\section{Giriş}

Martılar, Charadriiformes takımı Laridae familyasında bulunan ve ülkemizde özellikle Ege ve Marmara Denizi kıyılarında her mevsim görülen deniz kuşlarındandır (Demirsoy, 1992). Kanatlı cranium'u omurgalılar içerisinde çok fazla özelliğe sahiptir. Kemik kaynaşmalarının yanında pneumatizasyon ile kafanın hafifletilmesi, hareketli birleşmelerin bulunması, çok büyük iki orbita taşıması bunlardan bazılarıdır (Getty, 1975; King ve McLelland, 1984). Cranium kanatlılarda memelilerde de olduğu gibi neurocranium ve splanchnocranium olmak üzere iki bölüme ayrılır. Memelilerden farklı olarak kanatlı neurocranium'u os interparietale'yi içermez (Gültekin M, 1966). Kanatlı splanchnocranium'u ise memeli hayvanlarda bulunan kemiklere ilave olarak os premaxillare ve os quadratum'u içerir. Os ethmoidale neurocranium ve splanchnocranium kemikleri arasında yer almakta fakat suturaları kaybolduğundan, kemiklerin sınırlarının belirlenmesinde zorluk yaşanmaktadır (Nickel ve ark., 1986). Kuşların sınıflandırılmasında ve cinsiyetinin belirlenmesinde cranium ayırt edici bir özelliğe sahiptir (Dursun N, 2014; Koch ve Rossa, 1973).

Son yıllarda Multi Dedektör Bilgisayarlı Tomografi (MDBT) gibi medikal görüntüleme teknikleri önemli yapıların boyutsal ilişkilerini göstermede en çok kullanılan invaziv yöntemler arasında yer almaktadır (Freitas ve ark., 2011). Multi Dedektör Bilgisayarlı Tomografi, model oluşturmak ve morfolojik farklılıkları ortaya koymak için çeşitli morfometrik çalışmalarda kullanılmaktadır (Kindlmann ve ark., 2005; Turner ve ark., 2003). Cranium'da MDBT kullanılarak yüksek kaliteli kesitler elde edilip, anatomik ve patolojik veriler ayrıntılı olarak değerlendirilebilmektedir (Robina ve ark., 1991). Çeşitli görüntüleme teknikleri ile elde edilen iki boyutlu kesitlerin üç boyutlu hale getirilmesi işlemine rekonstrüksiyon adı verilir. Rekonstrüksiyon işlemi ile doku ve organların düzensiz olan yüzey görüntüleri daha detaylı olarak incelenebilecek hale getirilmektedir (Elad ve Einav, 1990; Mitchell HL., 1995; Özkadif S., 2011). Veteriner anatomi alanında MDBT kullanımı son 
yıllarda artmaya başlamakla birlikte kanatlı hayvanlarda da bu ileri görüntüleme teknikleri ile ilgili çeşitli çalışmalar bulunmaktadır (Dayan ve ark., 2014; Duymuş ve ark., 2013; Ekim ve ark., 2013; Onuk ve ark., 2013). Yapılan literatür taramalarında kanatlı hayvanların cranium'larına ait çeşitli anatomik çalışmalara rastlanılmıştır (Atalgın ve ark., 2014; Çakır A., 2001; İlgün ve ark., 2016 Özkan ZE., 2002; Özdemir ve ark., 2009). Martılar üzerinde de yapılan birçok anatomik çalışma bulunmasına rağmen (Coulson ve ark., 1983; Ince ve Pazvant, 2010; Ince ve ark., 2010; Ince ve ark., 2012) cranium'larına ait detaylı morfometrik bir çalışmaya rastlanılmamıştır.

$\mathrm{Bu}$ çalışmada, MDBT kullanarak martıların cranium'larının üç boyutlu rekonstrüksiyonunun oluşturulması, bu rekonstrüktif görüntüler üzerinden morfometrik ölçümlerin alınması, elde edilen verilerle Laridae spp.'nin hem martı türleri hem de diğer kanatlı türleri arasındaki farklılıkların ortaya koyulması, taksonomik ve zooarkeolojik olarak yapılacak diğer araştırmalara katkı sunması amaçlandı.

\section{Materyal ve Metot}

Bu çalışmada, İstanbul Üniversitesi Veteriner Fakültesi Vahşi Yaşamı Araştırma ve Koruma Kulübüne (VAŞAK) farklı zamanlarda tedavi amacıyla getirilmiş ve tedavinin cevap vermediği 15 adet ölü martı kullanıldı. Cinsiyet ve tür farkı gözetmeksizin toplanan ölü martıların cranium'ları gövdeden diseksiyon yöntemiyle ayrıldı. Çürüme ve bozulmanın önlenebilmesi amacıyla \%10'luk formaldehit solüsyonu içerisinde bekletildi. Martı cranium'ları Harran Üniversitesi Tıp Fakültesi Eğitim ve Araştırma Hastanesi Radyoloji Bölümü'nde 64 dedektörlü bilgisayarlı tomografi (General Electronic Revolution) cihazı ile 80 kv, $200 \mathrm{MA}, 639 \mathrm{mGY}$ ve $0.625 \mathrm{~mm}$ kesit kalınlığında tarandı. Elde edilen aksiyal kesitsel görüntülerden 3D reformat / rekonstrüksiyon görüntüler oluşturuldu. Oluşturulan bu 3 boyutlu görüntüler üzerinde aşağıda belirtilen ölçüm noktalarından osteometrik ölçümler alındı (Şekil 1, Şekil 2).

Cranium'a ait MDBT görüntüleri üzerinde alınan ölçüm noktaları;

CMU: Cranium'un maksimum uzunluğu (Protuberentia occipitalis externa ile apex premaxillaris arası mesafe)

CMY: Cranium'un maksimum yüksekliği (Basitemporale ile cranium'un en yüksek noktası arası mesafe)

CMG: Cranium'un maksimum genişliği (iki processus postfrontalis arası mesafe)

OmG: Orbitalar arası minimum genişlik (Dorsal yüzde iki orbita arası en küçük mesafe)
MMU: Mandibula'nın maksimum uzunluğu (Mandibula'nın apex ve aboral noktaları arası mesafe)

MFaU: Mandibula'nın apex ve facies articularis noktaları arasındaki mesafe

PU: Os premaxillaris (gaga) uzunluğu (Dorsal yüzde os premaxillaris'in apex ve aboral noktaları arası mesafe)

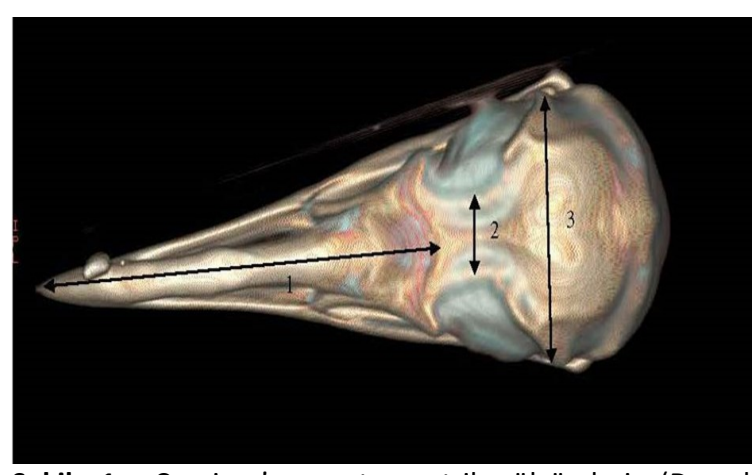

Şekil 1: Cranium'un osteometrik ölçümleri (Dorsal görünüş) 1:Os premaxillaris uzunluğu (PU), 2:Orbitalar arası minimum genişlik (OmG), 3: Cranium'un maksimum genişliği (CMG).

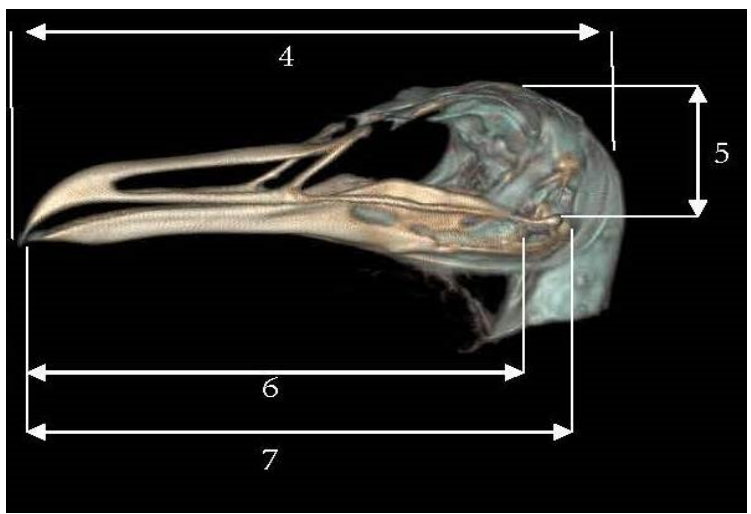

Şekil 2: Cranium'un osteometrik ölçümleri (Lateral Görünüş) 4: Cranium'un maksimum uzunluğu (CMU), 5: Cranium'un maksimum yüksekliği (CMY), 6: Mandibula'nın apex ve facies articularis'leri arası uzunluğu (MFaU), 7: Mandibula'nın maksimum uzunluğu (MMU).

Çalışmamızda kullanılan ölçüm noktaları Von Den Driecsh (1976) ve Dayan ve ark. (2014) ' nın çalışmalarına göre referans alındı. İncelenen özelliklerin ortalama değer ve standart sapması ile bu özelliklerin aralarındaki korelasyon katsayıları saptanarak istatistiksel değerlendirmeler yapıldı. İstatistiki değerlendirmelerde SPSS 22 programı kullanıldı. Terminolojide ise Nomina Anatomica Avium'dan (Baumel ve ark., 1993) yararlanıldı.

Çalışma izni Harran Üniversitesi Hayvan Deneyleri Yerel Etik Kurulu (HRÜ-HADYEK) (Karar No: 2018/001/01-03) tarafından alındı. 


\section{Bulgular}

Çalışmada, cranium'un ölçüm değerlerine ait ortalama değer ve standart sapma analizleri Tablo 1 'de ve bu ölçüm değerlerine ait korelasyon analizleri ise Tablo 2 ' de gösterildi.

Tablo 1. Cranium'a ait osteometrik ölçümlerin ortalama değer ve standart sapma analizleri.

\begin{tabular}{lc}
\hline $\begin{array}{c}\text { Osteometrik Ölçümler } \\
(\mathbf{m m})\end{array}$ & $\begin{array}{c}\text { Ortalama değer } \pm \text { Standart Sapma } \\
(\mathbf{n}: \mathbf{1 5})\end{array}$ \\
\hline CMU & $127.5 \pm 9.62$ \\
CMY & $31.9 \pm 2.12$ \\
OmG & $15.84 \pm 4,92$ \\
MMU & $108.12 \pm 7,65$ \\
MFaU & $101.88 \pm 7,36$ \\
CMG & $42.3933 \pm 2,09$ \\
PU & $65.0667 \pm 8,12$ \\
\hline
\end{tabular}

Tablo 2. Cranium'a ait osteometrik ölçümlerin korelasyon analizleri (* $\left.\mathrm{P}<0.05,{ }^{*} \mathrm{P}<0.01\right)$.

\begin{tabular}{lcccccc}
\hline & CMY & OmG & MMU & MFaU & CMG & PU \\
\hline CMU & 0,412 & 0,155 & 0,504 & 0,480 & 0,422 & $0,565^{*}$ \\
CMY & & 0,312 & $0,588^{*}$ & $0,609^{*}$ & $0,831^{* *}$ & 0,442 \\
OmG & & & 0,313 & 0,272 & 0,375 & $0,567^{*}$ \\
MMU & & & & $0,958^{* *}$ & $0,753^{* *}$ & $0,781^{* *}$ \\
MFaU & & & & & $0,773^{* *}$ & $0,643^{* *}$ \\
CMG & & & & & & $0,655^{* *}$ \\
\hline
\end{tabular}

Korelasyon ilişkileri incelendiğinde cranium'un maksimum genişliğinin (CMG); cranium'un maksimum yüksekliği (CMY) ve premaxillar (gaga uzunluğu) uzunluk (PU) ile arasında $(P<0.01)$ istatistiki önem tespit edildi. Mandibula'nın maksimum uzunluğunun (MMU); cranium'un maksimum genişliği (CMG), premaxillar (gaga uzunluğu) uzunluğu (PU) ve mandibula'nın facies articularis'e olan uzunluğu (MFaU) ile de aralarında oldukça önem taşıyan ilişki belirlendi $(P<0.01)$. Aynı zamanda CMU ile PU, CMY ile MMU ve MFaU OmG ile $P U$ arasında da $(P<0.05)$ düzeyinde istatistiksel bir ilişki tespit edildi.

\section{Tartışma ve Sonuç}

Yaptığımız çalışmada Laridae familyasına ait olan martıların cranium'larının MDCT görüntüleri üzerinden alınan ölçümlerinde istatistiki olarak önemli veriler elde edildi.

Dayan ve ark. (2014) ördek ve kaz cranium'larında yapmış oldukları çalışmada cranium'un maksimum uzunluğu (CGL) ile mandibula'nın maksimum uzunluğu (MGL) ve mandibula'nın facies articularis'e kadar olan uzunluk (Laf) arasındaki korelasyonların $\mathrm{P}<0.05$ ile $\mathrm{P}<0.01$ arasında değişkenlik gösterdiği belirlenmiş olup; martılarda almış olduğumuz ölçüm verilerinde bu değerler arasında önemli bir fark saptanmamıştır. Fakat aynı çalışmada ördek ve kazlara ait mandibula'nın en büyük uzunluğu (MGL) ile cranium'un en büyük genişliği (GB) ve mandibula'nın facies articularis'e kadar olan uzunluk (Laf) verileri arasındaki korelasyonlar bizim çalışmamıza paralel olarak $\mathrm{P}<0.01$ düzeyinde önemlilik göstermiştir. İlgün R. (2016), beç tavuğu ve hindilerde yapmış olduğu çalışmada os premaxillare uzunluklarını sırasıyla ortalama $21.02 \pm$ $1.10 \mathrm{~mm}, 23.32 \pm 2.20 \mathrm{~mm}$ olarak ölçmüş ve ikisi arasında $\mathrm{P}<0.01$ düzeyinde önem ilişkisi olduğunu belirtmiştir. Coulson ve ark. (1983) Herring Gull martı türünde bazı morfometrik ölçümlerin cinsiyet üzerindeki ilişkilerini araştırmış ve bunlardan gaga uzunluğunun ortalamasını dişilerde $49.5 \pm 2 \mathrm{~mm}$, erkeklerde ise $54.1 \pm 2.2 \mathrm{~mm}$ olarak bildirmiştir. Çalışmamızda martılarda os premaxillare' nin ortalama uzunluğunu $65.07 \pm 8.12 \mathrm{~mm}$ olarak ölçtük ve premaxillare uzunluğunun $\mathrm{MMU}, \mathrm{MFaU}$ ve $\mathrm{CMG}$ uzunlukları arasında $\mathrm{P}<0.01 ; \quad \mathrm{CMU}$ ve $\mathrm{OmG}$ uzunlukları ile ise arasında $\mathrm{P}<0.05$ düzeyinde bir önem ilişkisi olduğunu belirledik. Ortaya çıkan farklılıkların ise tür ve ırk farklılıklarından kaynaklandığı gibi, çalışmada kullanılan martıların farklı yaş ve cinsiyet grubuna ait olmasından kaynaklanabileceğini düşünmekteyiz.

Coulson ve ark. (1983) Herring Gull martılarında maksimum kafa uzunluğunu dişilerde $113.3 \pm 2.8 \mathrm{~mm}$, erkeklerde $124.2 \pm 3.4 \mathrm{~mm}$ olarak bildirmiştir. Araştırmamızda (Laridae spp.) cranium'un maksimum uzunluğu (CMU) ortalama $127.5 \pm 9.62 \mathrm{~mm}$ olarak ölçüldü ve bu verinin os premaxillare uzunluğu (gaga) (PU) ile arasındaki ilişkinin önemli olduğu tespit edildi $(P<0.05)$. Coulson ve ark. (1983)'nın belirlemiş olduğu değerle kıyaslandığında bizim verimizin ve ortalama değerinin yüksek tespitinin, farklı yaş ve cinsiyetteki martılardan veya birlikte tür farklılığından kaynaklanmış olabileceğini düşünmekteyiz.

Sonuç olarak martı cranium'larında MDBT görüntüleri kullanılarak alınan verilerde önemli istatistiki ilişkiler tespit edilmiştir. Böylece bu verilerin belirlenmesiyle martı cranium anatomisinin daha iyi anlaşılacağı, taksonomik yerinin belirlenmesinde referans veriler sunacağı ve bu konuda sınırlı olan litaratürlere katkı sağlanacağı düşünülmüştür.

\section{Teşekkür}

Bu çalışmaya katkılarından dolayı Harran Üniversitesi Tıp Fakültesi Radyoloji Teknikeri Seyfettin GÜNDÜZ' e, Veteriner Hekim Mehmet Ali ÖZCAN ve Mert ÇELIK 'e teşekkür ederiz. 


\section{Kaynaklar}

Atalgın ŞH, Büyükçopur Bozkurt EÜ, Kürtül I, 2014: A detailed evaluation of the skeletal elements of the skull in the grey heron (Ardea cinerea). Turk $J$ Vet Anim Sci, 38, 370-376.

Baumel JJ, King SA, Breazile JE, Evans HE, Berge JCV, 1993: Handbook of avian anatomy: NominaAnatomicaAvium, 2nd ed. Cambridge: NuttallOrnithological Club.

Coulson JC, Thomas C, Butterfield JEL, Duncan N, Monaghan P, Shedden C, 1983: The use of head and bill length to sex live gulls Laridae. Ibis, 125(4), 549557.

Çakır A, 2001: Kelaynak kuşunda (Geronticus eremita) neurocranium kemikleri. Türk Veteriner Hekimleri Birliği Dergisi, 72, 35-38.

Dayan MO, Demiraslan Y, Akbulut Y, Duymus M, Akosman MS, 2014: The morphometric values of the native duck and gooses' heads: A computed tomography study; Animal and Veterinary Sciences; Vol. 2, No. 6, 2014, pp. 175-178. doi: 10.11648/j.avs.20140206.13

Demirsoy A, 1992: Yasamin Temel Kurallari. Meteksan Anonim Sirketi, Ankara, ISBN: 975-7746-02-9, pp: 745-778.

Dursun N, 2014: Evcil Kuşların Anatomisi, Medisan Yayınları, Ankara.

Duymus M, Demiraslan Y, Akbulut Y, Orman G, Aslan K, Ozcan S, 2013: The Statistical Analysis of Some Volumetric Measurements in the Japanese Quails' Head with Different Feather Color: A Computed Tomography Study. Journal of the Faculty of Veterinary Medicine Kafkas University, 19, 681-686.

Ekim O, Oto C, Algın O, Bakıcı C, 2013: High resolution 3D magnetic resonance imaging of the visceral organs in chicken (Gallus domesticus) by 3 Tesla MR unit and 15-channel transmit coi1; Ankara Üniv Vet Fak Derg, 60, 229-233.

Elad D, Einav S, 1990: Three-Dimensional measurement of biological surfaces. ISPRS J Photogramm; 45: 247-66.

Freitas EP, Noritomi PY, Silva JVL, 2011: Use of rapid prototyping and $3 \mathrm{~d}$ reconstruction in veterinary medicine, advanced applications of rapid protoyping technology in modern engineering, Dr. $M$ Haque (Ed.), ISBN: 978-953-307-698-0, In Tech, Available from:http://www.intechopen.com/books/advanced -applications-of-rapid-prototyping-technology-inmodern-engineering/use-of-rapid-prototyping-and3d-reconstruction-in-veterinary-medicine

Getty R., 1975. Sisson and Grossman's the Anatomy of the Domestic Animals, 5 ed, Vol.2. London, UK: W.B. Saunders Company

Gültekin M, 1966, Evcil Memeli ve Kanatlıların Karşılaştırmalı Osteologia, 1. Baskı. Ankara, Ankara Üniversitesi Basımevi, 1966: 288-290

İlgün R, 2016: Beç Tavuğu (Numida meleagridis) ve Hindi (Meleagridis gallapova) Splanchnocranium'u Üzerinde Karşılaştırmalı Makro-Anatomik ve Morfometrik İncelemeler, FÜ Sağ Bil Vet Derg 30 (3), 171 - 175
Ince NG, Pazvant G, 2010: Martılarda larynx ve trachea üzerinde makro-anatomik çalışma. istanbul Üniversitesi Veteriner Fakültesi Dergisi, 36(2), 1-6.

ince NG, Pazvant G, Alpak H, 2012: Anatomical features of the syrinx in sea gulls. Ankara Üniversitesi Veteriner Fakültesi Dergisi, 59(1), 1-3.

Ince NG, Pazvant G, Kahvecioglu KO, 2010: Macro anatomic investigations on digestive system of Marmara Region sea gulls. Journal of Animal and Veterinary Advances, 9(12), 1757-1760.

Kindlmann GL, Weinstein DM, Jones GM, Johnson CR, Capecchi MR, Keller C, 2005: Practical vessel imaging by computed tomography in live transgenicmouse models for human tumors. Moleculer Imaging, 4, 417-424.

King AS and Mclelland J, 1984: Birds: Their Structure and Function. 2nd Edn, Bailliere Tindall, London, ISBN: 07020-0872-9, pp: 84-109.

Koch T, Rossa E, 1973: Anatomy of the Chicken and Domestic Birds The lowa State University Press, Ames. lowa.

Mitchell HL, 1995: Applications of digital photogrammetry to medical investigations. ISPRS J Photogramm; 50: 27-36

Nickel, R., Schummer, A., Seiferle, E., 1977. Anatomy of the Domestic Birds. Verlag Paul Parey Berlin pp: 6265.

Onuk B, Kabak M, Sahin B, Ince NG, Selcuk MB, 2013: New method for estimating the volume and volume fractions of the nasal structures in the goose (Anser anser domesticus) using computed tomography images. British Poultry Science, 54, 441-446.

Özdemir D, Özüdoğru Z, Can M, Sunar M, 2009: Balaban (Botaurus stellaris) ve Kızıl şahin (Buteo rufinus) neurocranium'u üzerinde karşılaştırmalı makroanatomik incelemeler. Atatürk Üniv Vet Fak Derg, 4, 169-175.

Özkadif S, 2011: Yeni Zelanda Tavşanlarında Sinus Paranasales'in Multidedektör Bilgisayarlı Tomografi Görüntülerinin Üç Boyutlu Rekonstrüksiyonu, Doktora tezi, SÜ Sağlık Bilimleri Enstitüsü, Konya.

Özkan ZE, 2002: Erkek ve dişi bıldırcınlarda (Coturnix coturnix) cranium üzerinde makro-anatomik ve osteometrik incelemeler. Kafkas Üniv Vet Fak Derg, 8 (2), 147-151.

Robina A, Regedon S, Guillen MT, Lignereux Y, 1991: Utilization of computed tomography for the determination of the volume of the cranial cavity of the Galgo hound. Acta Anatomica, 140, 108-111.

Turner $\mathrm{CH}$, Sun $\mathrm{Q}$, Schriefer J, Pitner N, Price R, Bouxsein ML, Rosen CJ, Donahue LR, Shultz KL, Beamer WG, 2003: Congenic mice reveal sex-specific genetic regulation of femoral structure and strength. Calcified Tissue International, 73, 297-303.

Von Den Driesch A, 1976: A Guide to the measurement of animal bones from archaeological sites. Peabody Museum Bulletin I. Cambridge M.A. Harvard University. pp: 31-34.

*Yazışma Adresi: İsmail DEMiRcioĞLU

Harran Üniversitesi, Veteriner Fakültesi, Anatomi

Anabilim Dalı, Şanlıurfa, Türkiye

e-mail: idemircioglu@harran.edu.tr 